\title{
К 70-летию Виктора Мироновича Ненахова
}

\author{
(C2021 А. В. Никитин ${ }^{凶}$ \\ Воронежский государственный университет, \\ Университетская пл.1. 394018, Воронеж, Российская Федерация
}

\begin{abstract}
Для цุитирования: Никитин А. В. К 70-летию Виктора Мироновича Ненахова // Вестник Воронежского государственного университета. Серия: Геология. 2021. №2. С. 116-119. DOI: https://oi.org/10.17308/geology.2021.2/3496
\end{abstract}

\section{To the $70^{\text {th }}$ anniversary of Viktor $M$. Nenahov}

\author{
(C2021 A. V. Nikitin ${ }^{凶}$ \\ Voronezh State University, 1 Universitetskaya pl., Voronezh 394018, Russian Federation
}

\begin{abstract}
For citation: Nikitin A. V. To the $70^{\text {th }}$ anniversary of Viktor M. Nenahov. Vestnik Voronezhskogo gosudarstvennogo universiteta. Seriya: Geologiya-Proceedings of Voronezh State University. Series: Geology, 2021, no. 2, pp. 116-119. DOI: https://doi.org/10.17308/geology.2021.2/3496

Conflict of interests: The author declares the absence of obvious and potential conflicts of interest related to the publication of this article.
\end{abstract}

Информацию о научной и административной деятельности Виктора Мироновича можно посмотреть в Интернете, я же хочу рассказать о нём как о человеке, с которым меня свела судьба более 30 лет назад.

Я познакомился с ним в 1991 г., когда Виктор Миронович по приглашению проф. В. И. Сиротина пришёл в ВГУ преподавать на кафедру Общей геологии. До этого, в течение шестнадцати лет (с 1975 по 1991 г.) он работал в Киргизии, где прошёл путь от рядового геолога до начальника Киргизского Геодинамического полигона, на котором повышали квалификацию геологи со всего Союза, и приобщались к мобилистской парадигме такие известные учёные как В. Е. Хаин, Н. В. Межеловский, Г. С. Гусев и многие другие.
Производственные отчёты, написанные под руководством Виктора Мироновича, и сегодня спустя 30 лет остаются актуальными. Подтверждением тому служат периодические звонки киргизских геологов, с просьбой проконсультировать по различным вопросам геологии.

В 1999 г. им совместно с ООО «Воронежгеология》 и Геологическим институтом РАН был создан Учебно-научно-производственный центр (УНПЦ), в рамках которого молодые преподаватели и студенты стали заниматься наукой и практикой на территории Воронежского кристаллического массива, в Забайкалье и на Алтае.

Контент доступен под лицензией Creative Commons Attribution 4.0 License. The content is available under Creative Commons Attribution 4.0 License.

\footnotetext{
Alexander V. Nikitin, e-mail: nikav_1960@mail.ru 
Приход Виктора Мироновича в Альма-матер вдохнул современные идеи и новое геодинамическое направление в работу кафедры, что отразилось впоследствии в её переименовании в кафедру “Общей геологии и геодинамики".

В смутные 90-е учебная практика первокурсников на Кавказе была полностью свёрнута и проходила только на Семилукском полигоне, но душа геолога рвалась в горы, да и студенты чувствовали свою ущербность, ограничиваясь изучением только платформенной геологии. Путём многочисленных перипетий и всяких (порой детективных) поисков места прак- тики, кафедра вышла на базу Ростовского госуниверситета, которая в то время была в очень плачевном состоянии: домики с дырявыми крышами, в которых ночью, во время дождя, чтобы не промокнуть приходилось неоднократно передвигать кровати, отсутствие электричества, панцирные сетки кроватей, проволокой прикрученные к неродным спинкам, а иногда и просто поставленные на местные валуны, приспособленные в качестве ножек. Питьевая вода, привозилась из родника, расположенного в километре от лагеря. Но всё это было не главное, а главное это - интересная геология и интересующиеся студенты (Фото. 1).

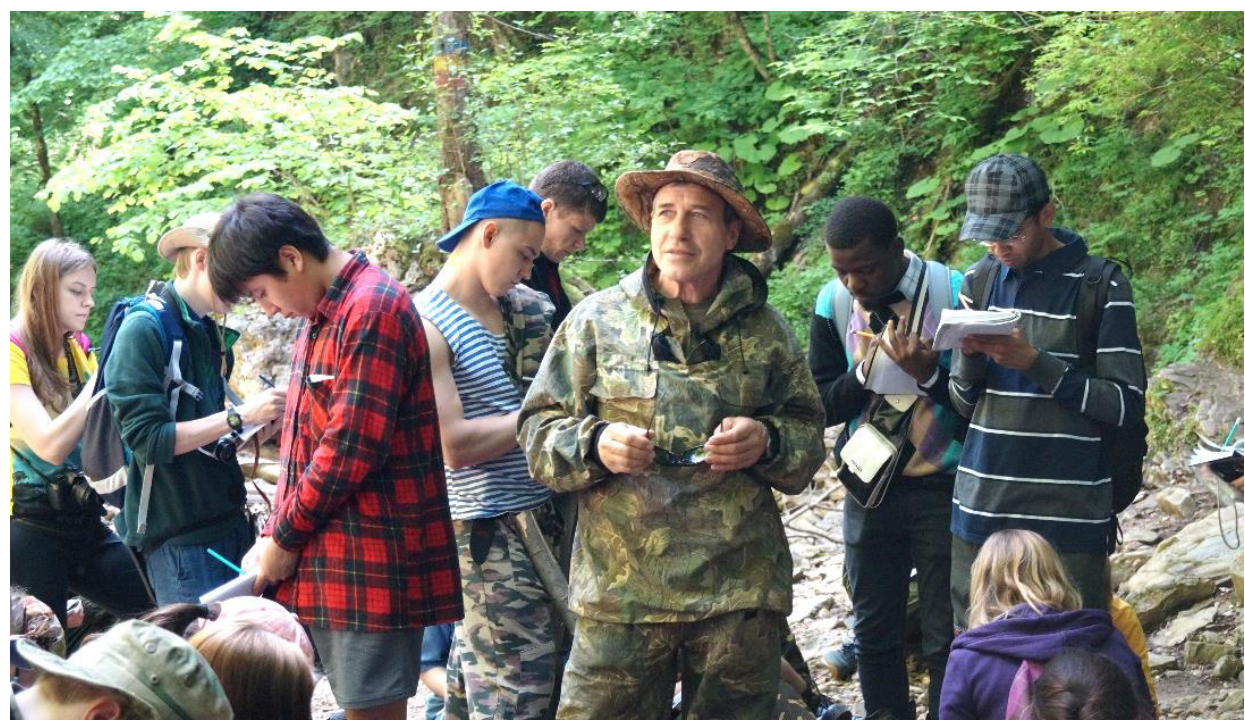

Фото 1. Обзорный маршрут по гранитоидам.

[Photo 1. Sightseeing route along the granitoids.]

Многие из тех, кто первыми «открывали» Кавказ (Бондаренко С. В., Золотарёва Г. С., Бухтоярова О. Н., Гордейченко Л.В.), впоследствии пополнили ряды преподавателей факультета.

Значение этой практики, кроме приобретения первичных навыков, заключается ещё и в том, что это начало, которое даёт первое и самое сильное впечатление о геологии, воспитывает интерес к профессии и приучает к коллективизму и взаимовыручке. Сейчас это полноценная база с комфортабельным жильём и интереснейшей геологией, которая ежегодно находит отражение в студенческих отчётах по практике, а также в многочисленных научных статьях и докладах на конференциях. Заслуга в том, что база живёт и развивается, целиком принадлежит Виктору Мироновичу Ненахову.

Маршруты и лекции после маршрутов, которые он читает студентам в процессе прохождении практики, настолько логичны и понятны, что завораживают не только их, но и меня, преподавателя с тридцатидвухлетним стажем. Они как хорошие книги, или фильмы, от которых невозможно оторваться и которые хочется слушать и смотреть бесконечно (Фото. 2).

Он всегда в кругу и во главе всех студенческих мероприятий, за что и пользуется заслуженным уважением, а задушевные вечерние разговоры у костра лучше любой политинформации воспитывают любовь к геологии, к своей Родине и осознания своего места в жизни.

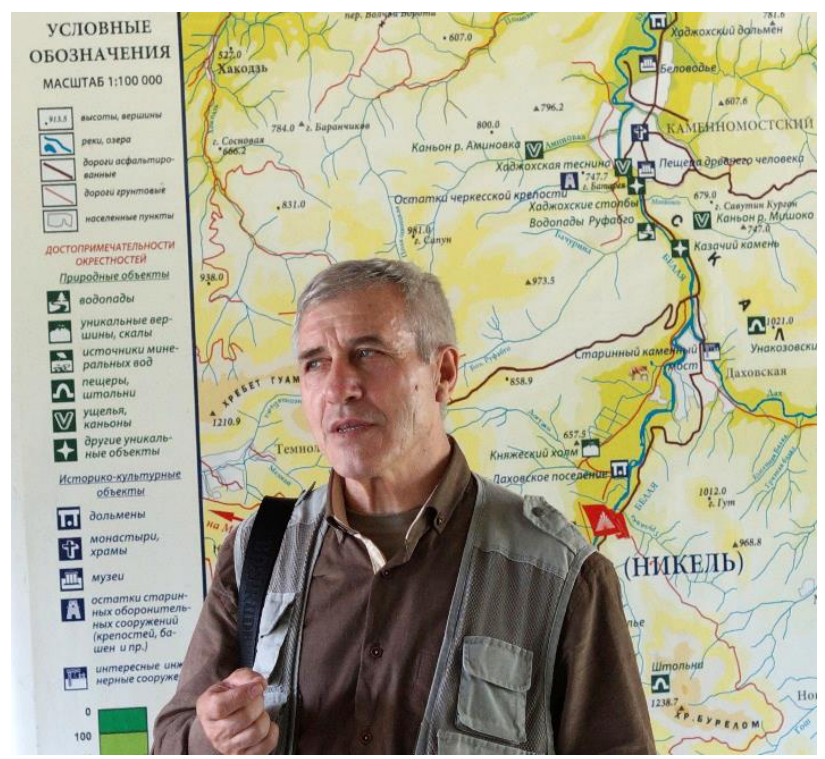

Фото 2. Лекция в «камералке».

[Photo 2. Lecture in "cameral office".] 
Хороший руководитель. Требователен и очень ответственен в профессиональных вопросах, но всегда корректен и выдержан. За три десятилетия совместной работы я никогда не слышал от него не только грубого, но даже резкого высказывания о ком-либо из своих коллег или подчинённых.

В 1999 г. в Воронеж из Бурятии приехала наша вы- пускница, ныне д.г.-м.н. Минина О. Р. и, узнав, что тот самый Ненахов, работа которого по хаотическим комплексам является их настольной книгой, работает в ВГУ, «попросила аудиенции». В результате Виктор Миронович согласился приехать в Забайкалье, чтобы непосредственно на конкретных обнажениях изучить проблему (Фото 3).

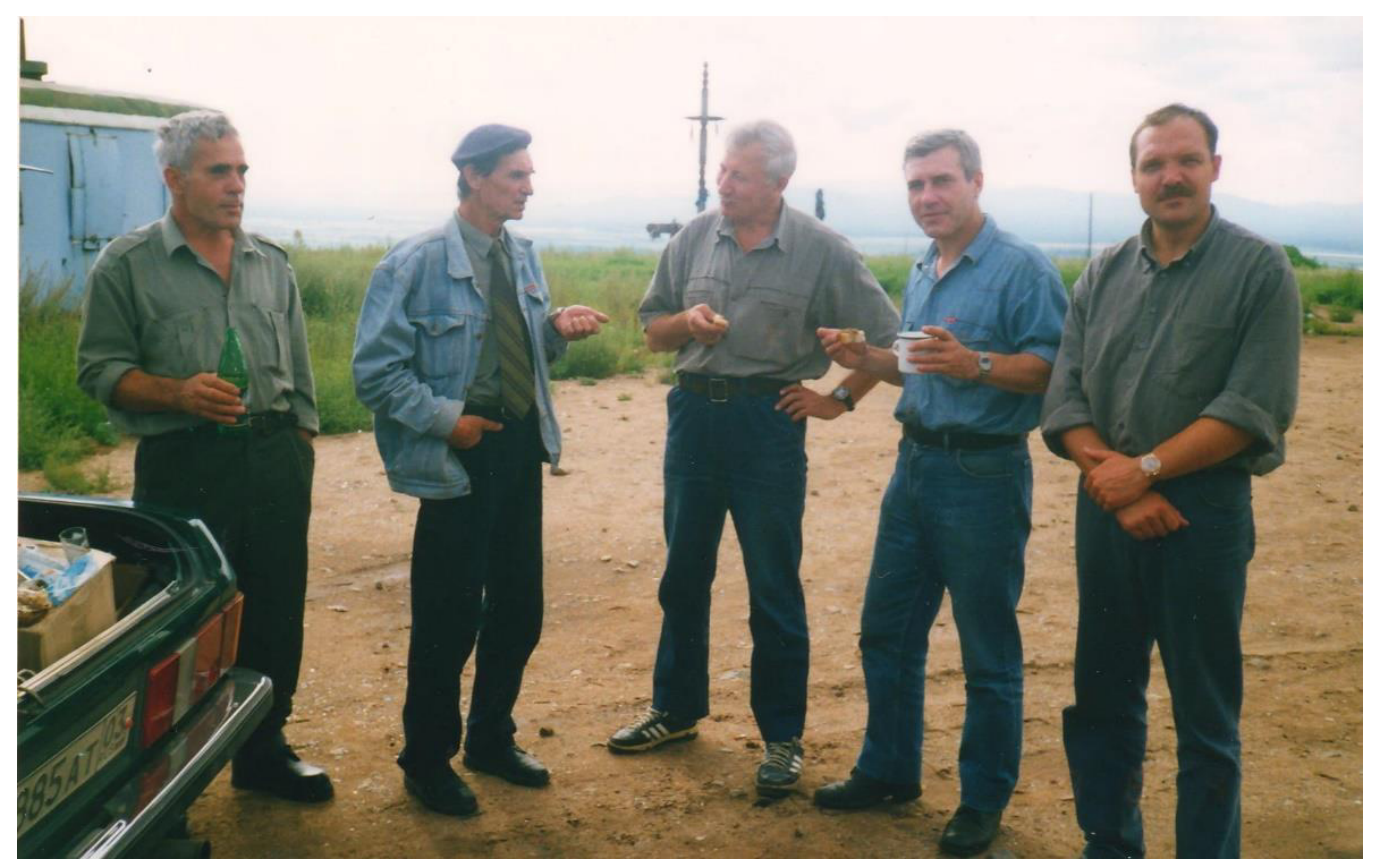

Фото 3. По дороге на Багдарин. Слева-направо: начальник экспедиции ФГУП «Бурятгеоцентр» Патрахин Г. П., главный геолог ФГУП «Бурятгеоцентр» Гусев Ю. П., редактор Серийной легенды Митрофанов Г. Л., проф. Ненахов В. М., преп. Никитин А.В. [Photo 3. On the way to Bagdarin. From left to right: head of the expedition of FSUE "Buryatgeocenter" G. P. Patrakhin, chief geologist of FSUE "Buryatgeocenter" Yu. P. Gusev, editor of the serial legend G. L. Mitrofanov, prof. Nenakhov V. M., lecturer Nikitin A. V.]

Так начался Бурятский этап его деятельности, который продолжался с 1999 по 2006 гг. Работы проводились в рамках ГДП-200 на территории Уакитской зоны Южно-Муйского золотоносного района, а затем и Джидинского рудного района, где изучались хаотические образования и магматические комплекса с выходом на геодинамическую обстановку их формирования, и в конечном счёте, на минерагению.

Отдельно хочу сказать, о его таланте принимать во внимание все мелочи, которые, как правило, отбрасываются «зашоренными» учёными со сформированной точкой зрения на ту или иную проблему. Так, например, в нашем совместном маршруте по водораздельной части г. Пайкада были последовательно разложены все собранные нами образцы, по которым он собрал «пазл» с выводами о строении и условиях образования этой структуры (Фото 4). Однако во второй части маршрута мы встретили пару пород, не укладывавшихся в первоначальную картину, в результате пришлось «скрепя сердце» ломать такую, казалось бы, логичную и красивую модель.

Виктор Миронович не только талантливый учёный - исследователь, но и прекрасный полевик, хорошо приспособленный к не всегда комфортной экспедици- онной жизни, и что самое главное - к жизни в коллективе. Неутомимый «трудоголик», как охарактеризовали его бурятские коллеги. Особенностью подхода к работе является универсальность, с какими бы геологическими проблемами он не сталкивался всегда, будь то стратиграфия, магматизм, тектоника и даже технология извлечения, Виктор Миронович со всей душой погружается в проблему, не перекладывая на других черновую работу.

И это не потому, что он не доверяет исполнителям, а потому что ему интересны все этапы исследований, начиная от первичной полевой обработки проб (с дешифрированием АФС, дроблением и промывкой протолочек, изучением минералов под бинокуляром и микроскопом), до тщательного анализа всех фактов, на основании которых делаются выводы.

Разносторонние интересы позволяют активно и плодотворно заниматься наукой и всегда находить интересную тему для изучения, будь то геодинамика Воронежского кристаллического массива, титан-циркониевые россыпи Тамбова, тектоника Кавказа, микститы Крыма, гранитоиды Забайкалья, медно-никелевые месторождения Камчатки, или золото Приморья (Фото 5). 


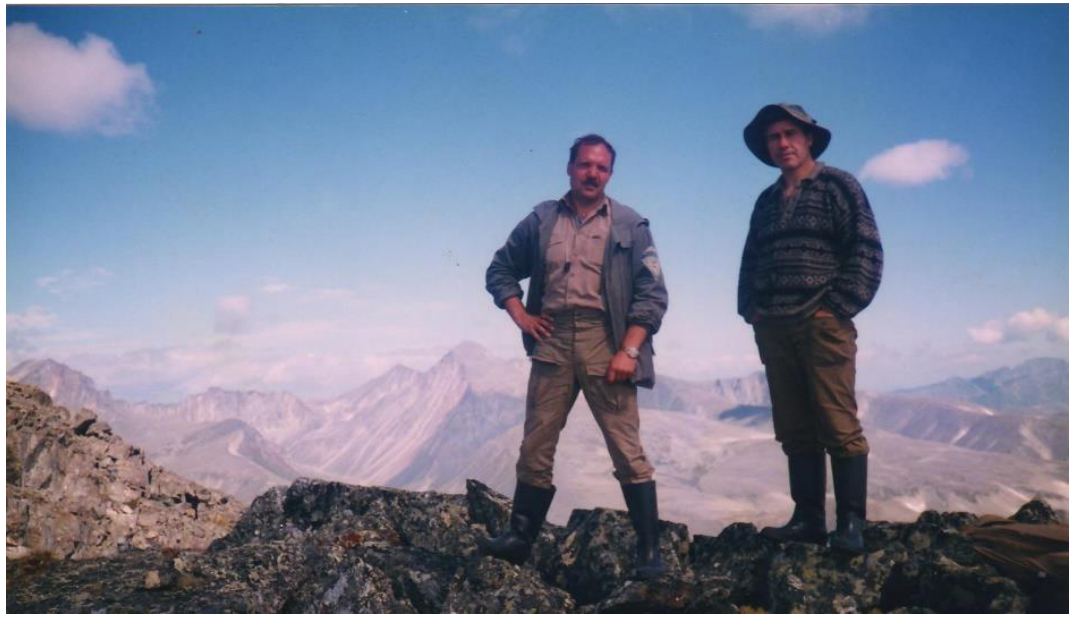

Фото 4. Южно-Муйский хребет (Бурятия).

[Photo 4. South-Muisky ridge (Buryatia).]

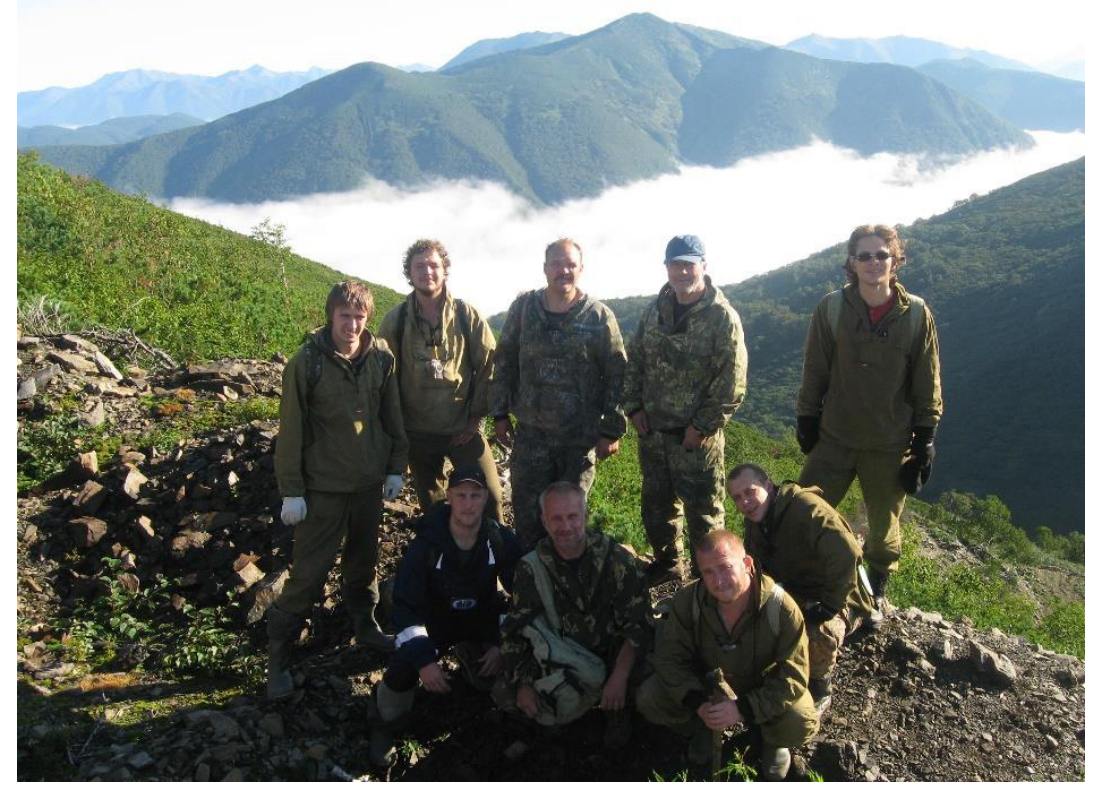

Фото 5. Поисковые работы на $\mathrm{Cu}$ и $\mathrm{Ni}$ (Камчатка).

[Photo 5. Prospecting work on $\mathrm{Cu}$ and $\mathrm{Ni}$ (Kamchatka).]

Под его активным руководством защитили кандидатские диссертации Никитин А. В., Ерёменко А. В., Бондаренко С. В., Золотарёва Г. С.

Вот и сейчас, он руководит аспирантами, занимаясь проблемой трудно извлекаемого кластерного золота. При этом многие приборы для проведения экспериментов создаёт и испытывает сам. Мне приходилось наблюдать, как он, засучив рукава (в буквальном, а не переносном смысле) отмучивает очередную партию глин.
Уважаемый Виктор Миронович! Коллектив геологического факультета Воронежского госуниверситета сердечно поздравляет Вас с днём рождения. Здоровья, интересных открытий, достойных Вас учеников и самое главное, неиссякаемого интереса к жизни и гармонии с самим собой и окружающим миром.

Конфликт интересов: Автор декларирует отсутствие явных и потенциальных конфликтов интересов, связанных с публикацией настоящей статьи.

Alexander V. Nikitin - PhD in Geol-Min., Associate Professor, Voronezh State University, Voronezh, Russian Federation; E-mail: nikav_1960@mail.ru;

ORCID https://orcid.org/0000-0002-2808-7887

Author have read and approved the final manuscript.
Никитин Александр Васильевич, к. г.-м.н., доцент кафедрь общей геологии и геодинамики, Воронежский государственный университет, Воронеж, Российская Федерация; E-mail: nikav_1960@mail.ru;

ORCID https://orcid.org/0000-0002-2808-7887

Автор прочитал и одобрил окончательный вариант рукописи. 